\title{
A compact field fluorometer and its application to dye tracing in karst environments
}

\author{
Amaël Poulain ${ }^{1}$ - Gaëtan Rochez ${ }^{1}$ - Jean-Pierre Van Roy ${ }^{2}$ - Lorraine Dewaide ${ }^{1}$. \\ Vincent Hallet $^{1}$ - Geert De Sadelaer ${ }^{3}$
}

Received: 21 June 2016 / Accepted: 19 November 2016/Published online: 20 March 2017

(C) The Author(s) 2017. This article is published with open access at Springerlink.com

\begin{abstract}
Dye tracing is a classic technique in hydrogeology to investigate surface-water or groundwater flow characteristics, and it is useful for many applications including natural or industrial issues. The Fluo-Green field fluorometer has been successfully tested in a karst environment and is specifically suitable for in-cave karst water monitoring. Karst research often uses dyes to obtain information about groundwater flow in unexplored cave passages. The compact device, alternatively named Fluo-G, meets the requirements of cave media: small $(10 \times 16 \times 21 \mathrm{~cm})$, lightweight $(0.75 \mathrm{~kg}$ without ballast $)$ and simple in conception. It is easy for cavers to set up and handle compared to other sampling methods. The fluorometer records uranine, turbidity and temperature with a user-defined time-step ( $1 \mathrm{~min}-1$ day). Very low energy consumption allows 9,000 measurements with six AA batteries. The device was calibrated and tested in the laboratory and in field conditions in Belgian karst systems. Results are in good fit with other sampling methods: in-situ fluorometers and automatic water sampling plus laboratory analysis. Recording high quality data (breakthrough curves) in karst with in-cave monitoring is valuable to improve knowledge of karst systems. Many hydrological and hydrogeological applications can benefit from such a low-cost and compact device, and finding the best compromise between resources and quality data is
\end{abstract}

Amaël Poulain

amael.poulain@unamur.be

1 Department of Geology, University of Namur, Rue de Bruxelles No. 61, B-5000 Namur, Belgium

2 Department of Physics, University of Namur, Rue de Bruxelles No. 61, B-5000 Namur, Belgium

3 Royal Meteorological Institute of Belgium, Avenue Circulaire No. 3, B-1180 Bruxelles, Belgium essential. Several improvements are possible but preliminary field tests are very promising.

Keywords Tracer tests - Field technique - Fluorometer · Groundwater monitoring · Karst

\section{Introduction}

Many scientific fields use tracer tests to understand the flow organization and characteristics of water. This tool can answer multiple questions for both surface water and groundwater studies (Käss 1998). The fields of environmental management and engineering can also benefit from dye tracing to answer multiple questions about flow connections, catchment area, aquifer vulnerability, pollution and construction leakages. In the karst environment, they represent a powerful tool for the determination of an unexplored system configuration (Goldscheider et al. 2008). Hydraulic connections, catchment area or transit time can be easily obtained from dye tracing (Meiman et al. 2001; Lauber et al. 2014). In this context, fluorescent dyes tend to approach the "ideal tracer" as they are reasonably conservative, safe, inexpensive and highly detectable (Benischke et al. 2007). Uranine is for now the most commonly used tracer because of these characteristics.

The objectives and context of the dye tracing in karst areas are two key elements to determine the right sampling approach (Smart 2005). Qualitative and semi-quantitative methods like visual detection and activated charcoal answer geographical issues (connections, catchments, travel time) with limited material resources. Charcoal bags are broadly used because they are cheap and easy to implement but are subject to contamination. They are mainly valuable for preliminary tests and inaccessible sites (Goldscheider et al. 2008). 
Quantitative methodologies give more valuable information because frequent water sampling allows the measurement of dye concentration in time. These data are instructive regarding the hydrogeological issue and for cave exploration. Automatic water samplers optimize the sampling task and improve the temporal resolution of data. Nevertheless, sampling, handling and analyzing water samples remains a significant task, even more with multiple sampling stations.

More recently, automatic field fluorometers have given the opportunity to make in-situ measurements of fluorescent dyes in water (Schnegg 2002). The temporal resolution, precision and accuracy are significantly enhanced. Furthermore, those devices reduce the need of frequent handling in the field due to automatic recording over an extended period of time. Another advantage of this in-situ measurement is the absence of transportation and analysis of bottled samples.

As discussed by Smart (2005), the dye tracing and specifically the sampling design has to be defined regarding the objectives and the scientific, socio-economic and logistic context. The first objective for cavers and karst researchers is geographical: flow routes, karst catchments, travel times. In addition, hydrogeological objectives can bring valuable data for cave research: velocity, dispersion, storage, conduits characteristics and possible retardation (Dewaide et al. 2016). In this context, cave researchers aim to run with limited technical, financial and personnel resources (Smart et al. 1998). Error tolerance and data resolution will depend upon the audience and the objectives but primarily it must be cost-effective. In-situ fluorometers tend to be the most valuable technique in terms of quality data relative to costs.

This paper presents the Fluo-Green, a recently developed fluorometer for hydrological investigations. The device can be used in variable environments but it has been specifically designed and tested for karst. In-cave monitoring can bring more detailed insights into the internal structure of karst aquifers (Goldscheider et al. 2008); nevertheless, cave access is often difficult and monitoring operations are few and under-exploited (Lauber et al. 2014).
The best compromise has to be found between quality data (precision and accuracy) and costs regarding the objectives and requirements of the research issue. The question of the benefit of increasing data quality compared to the customer needs has to be asked. For "simple" geographical and hydrogeological issues, experimenter's expectations can be lowered with simplified material.

The Fluo-Green device, or Fluo-G, was designed by G. De Sadelaer in 2015. Laboratory calibrations and field tests were successfully conducted in 2015 and 2016 at the University of Namur in cave systems of Belgium. Comparisons with other sampling methods in variable sampling environments allowed the evaluation of the field performances of this new device.

\section{Description of the Fluo-G}

The Fluo-G fluorometer is a two-in-one device with in-situ fluorescence measurement and data logger in the same box (Fig. 1). The device is compact $(10 \times 16 \times 21 \mathrm{~cm})$ and extra light $(0.75 \mathrm{~kg}$ without ballast). The measurement is made through a transparent casing with an excitation-detection unit. The excitation unit comprises a set of two LEDs, and wavelengths are selected for uranine excitation (470 nanometers [nm], 6,300 millicandela [mcd]) and turbidity measurement $(625 \mathrm{~nm}, 6,500 \mathrm{mcd})$. The Fluo-G is designed to measure uranine only, since it is the most common fluorescent dye in karst hydrogeology and cave exploration. Other fluorescent dyes could easily be measured by choosing another LED wavelength for the excitation unit and applying the adequate calibration procedure. The detection unit is right next to the excitation unit and has a RGB (red-green-blue) sensor perpendicular to the light source. Detection and correction of turbidity and a water temperature probe are also integrated.

Excitation and detection sequences are controlled by an Arduino coupled to a data logger shield with a microSD memory card. A real-time clock is used to wake up the fluorometer and run the measurement at a defined time-step. A minimum

Fig. 1 Photograph and schematic view of the Fluo-Green fluorometer

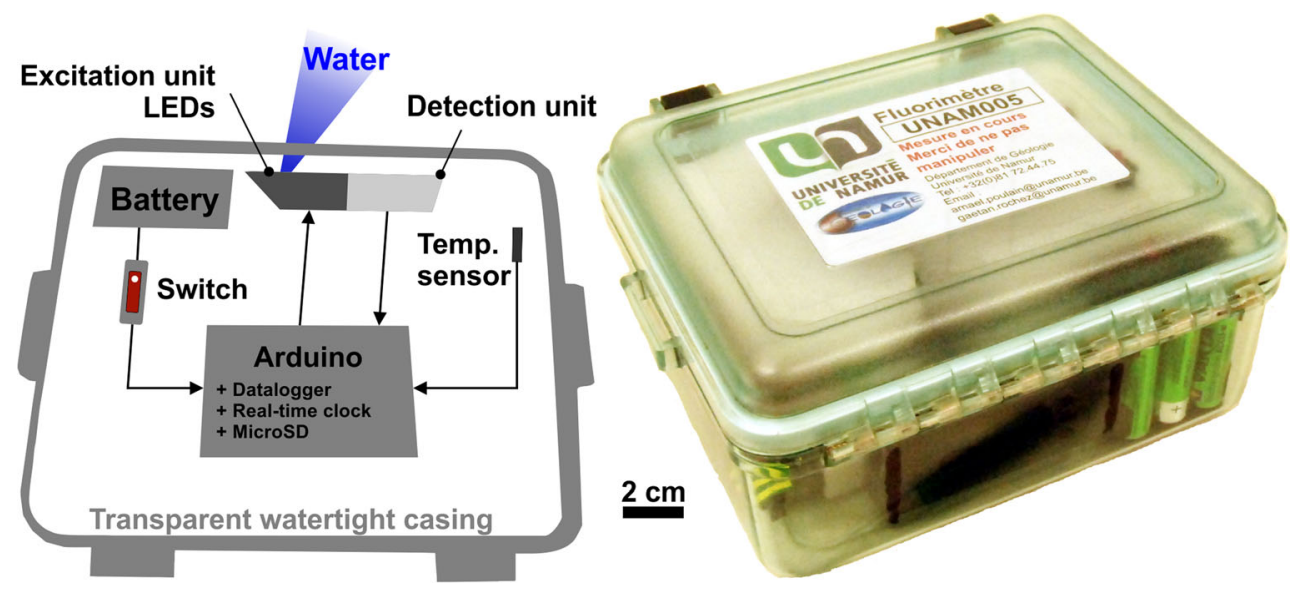


time step of $1 \mathrm{~min}$ allows to record high quality data for further interpretation. The energy consumption is $0.2 \mathrm{mAh}$ per measurement and the device is turned off between measurements. Six AA batteries (1,800 mAh) give 30 days of lifetime with a measurement time-step of $5 \mathrm{~min}$. Before each sequence of excitation, the detection unit makes one dark measurement to allow a possible daylight correction. Main characteristics of the Fluo-G are given in the Table 1. A comparison is made with the GGUN FL30 of Albillia Switzerland since it is a standard commercial instrument for in-situ dye-tracing monitoring.

As mentioned in the Table 1, the main advantages of Fluo$\mathrm{G}$ are the compact size and the low energy consumption allowing extended monitoring. Disadvantages are a small number of detectable dyes (GGUN FL30 has more channels) and a smaller maximal depth of use. The latter is limited by the tightness of the transparent casing, which is one of the main possible deficiencies of the Fluo-G and has to be improved in the future. GGUN-FL30 also has detection threshold and resolution that are somewhat better than the Fluo-G. Advantages and disadvantages of the Fluo-G compared with other monitoring methods will be discussed later.

Data acquisition is automatically started at connection of the battery. No external connections are needed during normal use of the fluorometer. Raw measurement data are stored on the internal microSD memory card as a text file. The data can be read into spreadsheet software to apply calibration parameters and get the results in $\mathrm{ppb}$ or $\mu \mathrm{g} / \mathrm{liter}$.

\section{Laboratory calibration}

\section{Standard calibration procedure}

Calibration of the Fluo-G is recommended before every experiment to guarantee data quality. The calibration procedure evaluates the response of the sensor with respect to the water of the monitored site. The background fluorescence can also be removed to avoid misinterpretation and get the real concentration of fluorescent dye.

This calibration is applicable when using a single color dye tracer. Although it is possible to use other tracers, the device was calibrated for uranine. Uranine has a very low minimal detectable signal, so the sensitivity is high compared to other tracers (Smart et al. 1998). Due to cost compromises, no extra filters were installed in the optical detection path, which will lead to a supplementary offset signal (see 'Correction for stray light' section).

Figure 2 shows the relationship between the concentration of the tracer $(u)$ and the $\mathrm{G}$ channel output signal of the detector that has been fitted with a second order polynomial. The $R^{2}$ is 0.999 so the model fits the experimental data quite perfectly. The general equation for the calibration is:

$u=C 1 \times G^{2}+C 2 \times G+C 3$

where the following terms and definitions apply:
Table 1 Properties of the FluoGreen and comparison with the GGUN FL30 (Schnegg 2002)

\begin{tabular}{|c|c|c|}
\hline Properties & Fluo-Green & $\begin{array}{l}\text { GGUN FL30 } \\
\text { (Schnegg 2002) }\end{array}$ \\
\hline Size & $10 \times 16 \times 21 \mathrm{~cm}$ & $\begin{array}{l}\text { Probe : } 16 \times 17 \mathrm{~cm} \\
\text { Logger : } 29 \times 25 \times 19 \mathrm{~cm}\end{array}$ \\
\hline Weight & $0.75 \mathrm{~kg}$ & $\begin{array}{l}\text { Probe : } 7.3 \mathrm{~kg} \\
\text { Logger : } 7.2 \mathrm{~kg} \\
\text { Cable : } 1 \mathrm{~kg} / 10 \mathrm{~m}\end{array}$ \\
\hline Internal ballasts & $2 \times 1.0 \mathrm{~kg}$ & - \\
\hline Channels & $\begin{array}{l}2(470 \text { and } 625 \mathrm{~nm}) \\
\text { Uranine and turbidity }\end{array}$ & $\begin{array}{l}4(370,470,525 \text { and } 660 \mathrm{~nm}) \\
3 \text { tracers + turbidity }\end{array}$ \\
\hline Turbidity measurement & $0.08-200 \mathrm{NTU}$ & $0.02-400 \mathrm{NTU}$ \\
\hline Time resolution & $1 \min -1$ day & $2 \mathrm{~s}$ ( 1 channel $)-15 \mathrm{~min}$ \\
\hline Duration of measurement sequence & $\begin{array}{l}\text { Total } \\
\quad \text { measurement }=9.4 \mathrm{~s}\end{array}$ & $2 \mathrm{~s} /$ channel \\
\hline Consumption & $\begin{array}{l}77 \mathrm{~mA} \text { (measurement) } \\
0 \mathrm{~mA} \text { (stand by) }\end{array}$ & $\begin{array}{l}50 \mathrm{~mA} \text { (measurement) } \\
1.5 \mathrm{~mA} \text { (stand by) }\end{array}$ \\
\hline Detection resolution (uranine) & $0.06-0.09 \mathrm{ppb}$ & $0.02 \mathrm{ppb}$ \\
\hline Saturation threshold & $3,000 \mathrm{ppb}$ (theoretical) & $2,500 \mathrm{mV}$ \\
\hline Contamination & Impossible & Impossible \\
\hline $\begin{array}{l}\text { Temperature probe resolution (field } \\
\text { measurement) }\end{array}$ & $0.06^{\circ} \mathrm{C}$ & $0.01^{\circ} \mathrm{C}$ \\
\hline Max depth of use & Tested at $-4 \mathrm{~m}$ & $-50 \mathrm{~m}$ \\
\hline
\end{tabular}




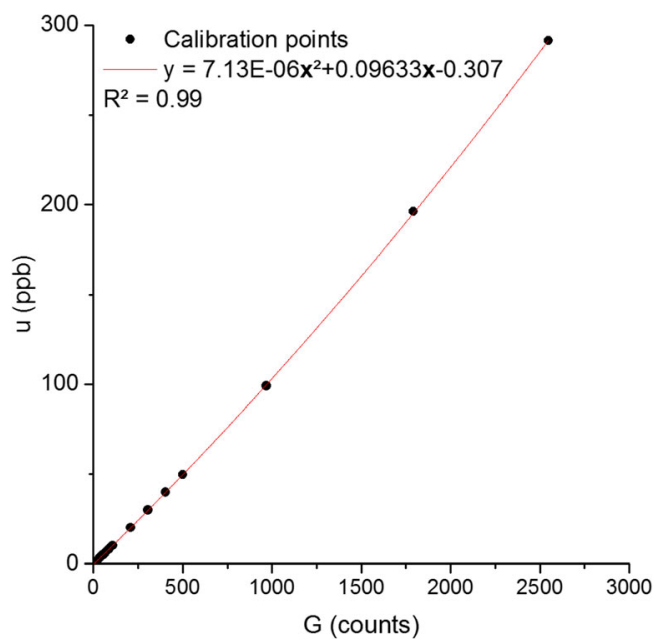

Fig. 2 Calibration curve for the Fluo-Green showing the relationship between uranine concentration $(u)$ and $\mathrm{ADU}$ counts of the detection unit $(G)$

$u(\mathrm{ppb}) \quad$ Concentration of the uranine dye

$G \quad$ The corrected ADU value detected by the green

(counts) channel (see 'Correction for stray light' section; ADU: analogue digital units, the result of an A/D conversion, also called arbitrary digital units)

$C 1, C 2$, Constants derived after calibration curve fitting. C3 Here the minimum resolution of the sensor is $0.09 \mathrm{ppb} /$ count. A routine calibration can be limited to a three-point calibration at 1, 10 and $100 \mathrm{ppb}$ and an offset measurement at $0 \mathrm{ppb}$.

\section{Correction for stray light}

Stray light from surrounding light and the excitation LED enters the detector directly, via reflections or by water turbidity. This interference will produce a variable (high) offset signal at the output of the detector. It is necessary to correct this interference in order to obtain reliable data.

A classical filter fluorometer uses filters with a high optical density to avoid any offset signal. The Fluo-G setup has a limited optical density, and a reference channel is used to correct the green detector output signal (ADU). Due to the quasi-identical optical path, stray light is detected identically by all three detector channels (red, green and blue) with exception of a gain difference and a very small zero offset. This property makes a good offset correction possible. The compensation will lead to a corrected $\mathrm{G}$ channel with a zero error of \pm 1 count. Correction of surrounding light (daylight or artificial lights) is done by a dark background measurement with all LED off (no excitation). The green detector output (ADU) measured with no excitation is subtracted from the signal measured when the excitation is on. The correction amplitude of artificial lighting is visible on Fig. 5.

\section{Turbidity}

Turbidity will influence the measured tracer emission signal in two ways:

- Light from the excitation LED will be scattered to the emission detector (offset). This offset is already corrected by the method already described.

- Excitation and emission light will be absorbed (gain). The influence of turbidity on the measured uranine concentration has to be determined during the turbidity calibration, and a correction is applicable.

Turbidity is measured in a wavelength that is not influenced by tracer excitation/emission spectra; here a red LED at $625 \mathrm{~nm}$ is used.

\section{Field tests}

Rather than laboratory tests and calibrations, field tests were needed to validate the fluorometer. Precision and accuracy are important parameters to be tested in the cave environment to evaluate their consistency with the objectives and context of the tracing (Smart 2005). The Fluo-G has been tested in the framework of hydrogeological studies in 2015 and 2016 at the University of Namur (Belgium). Four experiments were conducted into different karst systems of southern Belgium (Fig. 3). Different sampling environments were selected:

- A surface karst resurgence with daylight interference

- An underground river with a pebble riverbed, high water current and artificial lighting

- An underground river with a mud riverbed and very low water current

- Drip-water from a stalactite

The Fluo-G was coupled to additional sampling methods in order to compare monitoring results. An automatic water sampler and laboratory spectrofluorometer was used for test No. 1 . A GGUN FL30 fluorometer (Schnegg 2002) was used for test No. 2. All fluorometers and the spectrofluorometer were calibrated using the site blank water and the same uranine.

\section{Test No. 1: surface karst resurgence with daylight interference}

The Haquin karst system (Lustin) was investigated during the first test (Fig. 3b). It is a 3-km-long sinkhole-resurgence system in Frasnian limestones of southern Belgium. The resurgence was equipped with an automated water sampler with a 1 -h time step during $48 \mathrm{~h}$. Water samples were analyzed with 
Fig. 3 Maps of the study sites. a Location of the test sites within the southern Belgium limestones. b Location of test Nos. 1 and 3 in the Frasnian limestones of the Meuse valley. c Location of test Nos. 2 and 4 in the Givetian limstones of the Lomme Valley. $\mathbf{d}$ Cross-section in the Rochefort cave showing the surface-to-cave dye tracing (No. 4) in the Givetian limestones

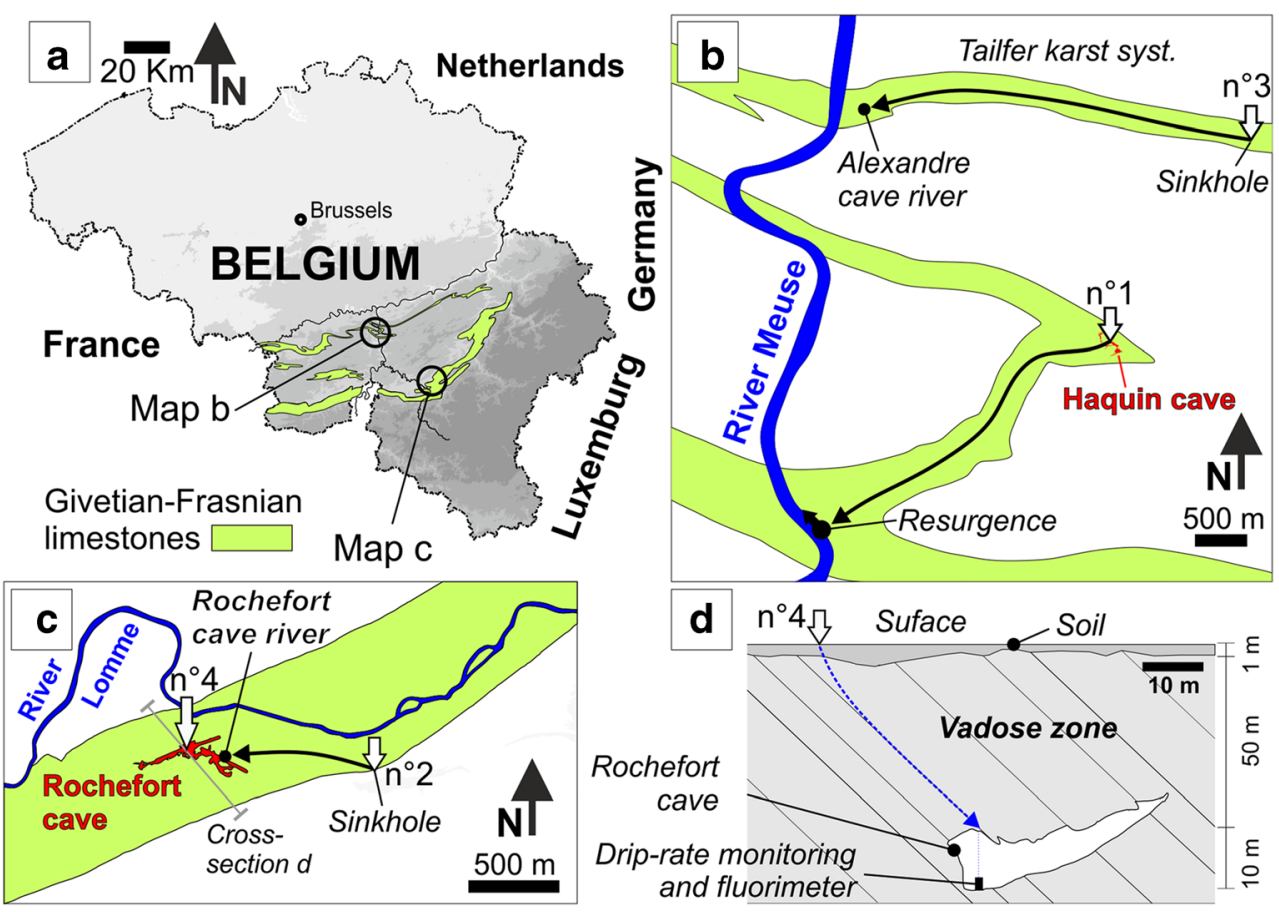

an Agilent spectrofluorometer at the University of Namur. Three Fluo-G were installed in the resurgence with a 5-min time-step configuration.

The three Fluo-G breakthrough curves show similar results after correction with calibration formulas (Fig. 4). In-situ measurements are also in good fit with results from the laboratory spectrofluorometer. The first arrival-of-tracer events are similar and the maximum concentration difference is $0.2-0.8 \mathrm{ppb}$. Those results show the ability of the Fluo-G to give reliable data in terms of precision (the three devices give the same results) and accuracy (as the spectrofluorometer value is expected to be the most accurate measurement).

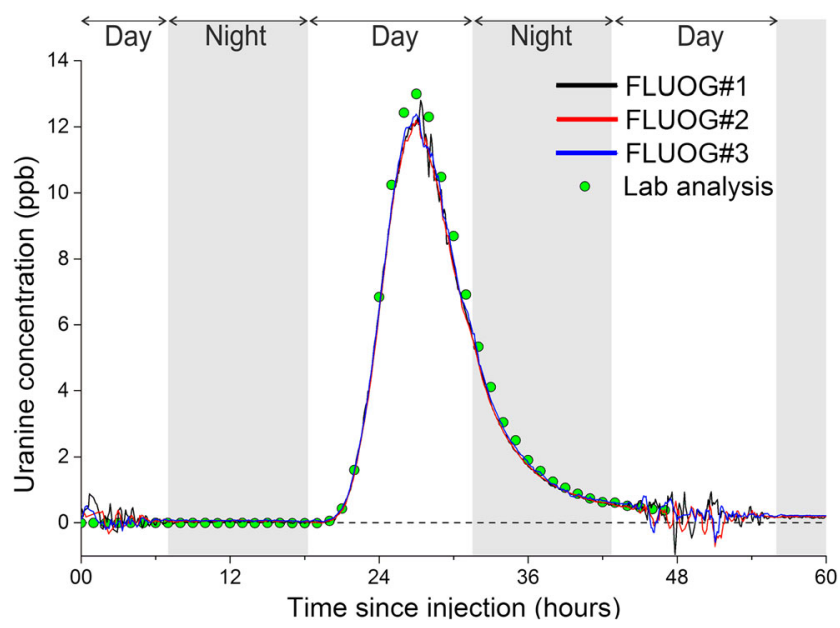

Fig. 4 Breakthrough curves for test No. 1. Comparison between spectrofluorometer laboratory analysis on water samples (green dots) and three Fluo-G in-situ fluorometers (FLUOG\#1, 2, 3). The influence of daylight on the Fluo-G measurement is visible
An important daylight noise is observable in all the breakthrough curves. The dark measurement allows a partial correction and the BTC is easily distinguishable from the noise; nevertheless, a daylight coverage should be implemented for surface measurements. Additional smoothing of the data can easily remove residual daylight noise.

\section{Test No. 2: underground river with pebble riverbed, high} water current and artificial lighting

The second field test was conducted in the Givetian limestones of the Lomme karst system (Fig. 3c). The Fluo-G and a GGUN-FL30 field fluorometers were installed in the Rochefort cave underground river $(50 \mathrm{~L} / \mathrm{s})$. This river has high current and a pebble riverbed. Uranine was injected in a small sinkhole $1 \mathrm{~km}$ upstream and the GGUN FL30 fluorometer (Schnegg 2002) was used for comparison as it is a reference in modern submersible fluorometers (Goldscheider et al. 2008).

Figure 5 shows the strong similitude between the GGUN FL30 and the Fluo-G BTCs. Basic features of the restitution are the same: time of first arrival $(24 \mathrm{~h})$, peak time $(33 \mathrm{~h})$ and maximum concentration (difference of $0.7 \mathrm{ppb}$ ). Total restitution difference is $3.3 \%$ between the first arrival and $t=100 \mathrm{~h}$. Stray light induced by artificial lighting in the cave is visible on the uncorrected Fluo-G breakthrough curve (Fig. 5a). The dark measurement allows for the removal of this interference as illustrated in Fig. 5b. A signal noise of $\pm 0.05 \mathrm{ppb}$ is visible on the Fluo-G BTC. This noise is less visible on the GGUN curve; however, this variability does not affect the interpretation of the results. 

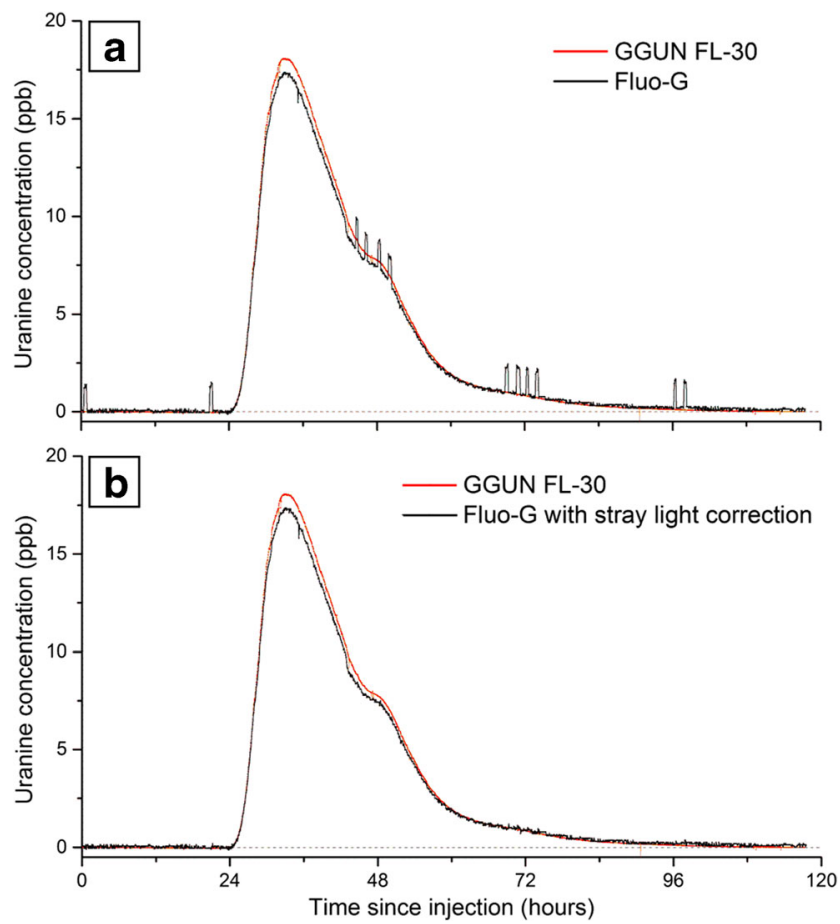

Fig. 5 Breakthrough curves for test No. 2. Comparison between in-situ fluorometers Fluo-G and GGUN FL30. a Fluo-G data without stray light correction. b Fluo-G data with stray light correction (via dark measurement)

\section{Test No. 3: underground river with mud riverbed and low} water current

The third test was made in the Tailfer karst system (Fig. 3b), which is similar to the Haquin system (test No. 1) in terms of geologic context and size. The Fluo-G has been installed in the small underground river of the Alexandre cave. This river has a muddy riverbed and almost no visible water current. High water turbidity was observed during the measurement. The BTC of this experiment is displayed in Fig. 6.

The shape of the BTC is characteristic of a karst stream dominated by advection and dispersion. The dye restitution is clearly visible despite the very low tracer concentration. The maximum concentration is $0.8 \mathrm{ppb}$ with a background fluorescence signal ranging from 0 to $0.1 \mathrm{ppb}$. The result of this test shows the ability of the Fluo-G to detect small concentrations of uranine despite the basic design of the excitation/ detection unit. This low restitution threshold allows one to use less tracer which is both a financial advantage and also avoids visual contamination. Figure 6 also shows the measurement error with the Fluo-G, ranging from 0.06 to $0.09 \mathrm{ppb}$. Although this could become an issue to detect small changes in fluorescence signal, it can be easily overcome by using more dye during injection. For this case, the error/peak concentration ratio is $1 / 8$ and allows a precise determination of BTC characteristics.

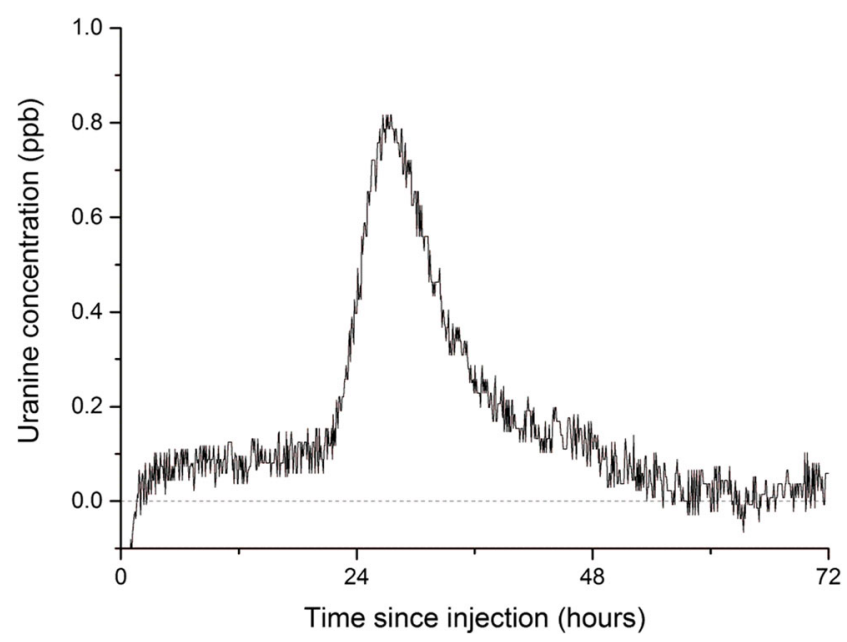

Fig. 6 Breakthrough curve (BTC) for test No. 3. Result shows a typical BTC of an advective karst system despite a tracer concentration lower than $1 \mathrm{ppb}$

Test No. 4: drip-water monitoring for vadose zone tracing

A vadose zone tracing test was performed in the Rochefort cave of the Lomme karst system (Fig. 3c,d). Uranine was injected at the surface and the monitoring (drip-rate, uranine) was made under a perennial stalactite $(5-25 \mathrm{~L} / \mathrm{h}), 50 \mathrm{~m}$ below. The Fluo-G was submerged into a small bath $(5 \mathrm{~L})$ collecting drip-water.

Figure 7 shows the parameters recorded with the Fluo-G in the stalactite drip-water: battery voltage, water temperature and uranine concentration. Additional parameters such as surface rainfall, surface temperature and stalactite drip-rate are also displayed in order to properly interpret the Fluo-G results.

The Fluo-G successfully records uranine concentration and water temperature for 30 days; an additional battery can be used, allowing 2 months of measurement with a 5 -min time-step. Extended lifetime is due to the very low energy consumption of Fluo-G and is crucial for long-term experiments or remote study sites (Poulain et al. 2015). The small size of the device allows one to make the measurements in a small bath, which tends to avoid concentration buffering for drip-water monitoring. The temperature signal recorded by the fluorometer shows a resolution of $0.06{ }^{\circ} \mathrm{C}$, which is precise enough to allow a good correlation with surface air temperature in this case. Field temperature measurement with the GGUN shows a resolution of $0.01{ }^{\circ} \mathrm{C}$, which can be useful in case of low variability signals.

\section{Advantages and disadvantages of the Fluo-G}

This new device has the same kinds of advantages as any other field fluorometer: extended autonomy, data resolution, no water bottle to handle, no contamination or tracer degradation, no freezing sensitivity and reduced dye tracer mass to inject. Basically, the direct measurement of the tracer concentration 
Fig. 7 Surface and cave parameters recorded during test No. 4. Fluo-G parameters are displayed on the left axis: battery voltage (Volts), drip-water temperature $\left({ }^{\circ} \mathrm{C}\right)$ and uranine concentration (ppb). Other parameters are displayed on the right axis: surface rainfall $(\mathrm{mm} /$ $\mathrm{h})$, surface air temperature $\left({ }^{\circ} \mathrm{C}\right)$ and stalactite drip-rate $(\mathrm{L} / \mathrm{h})$

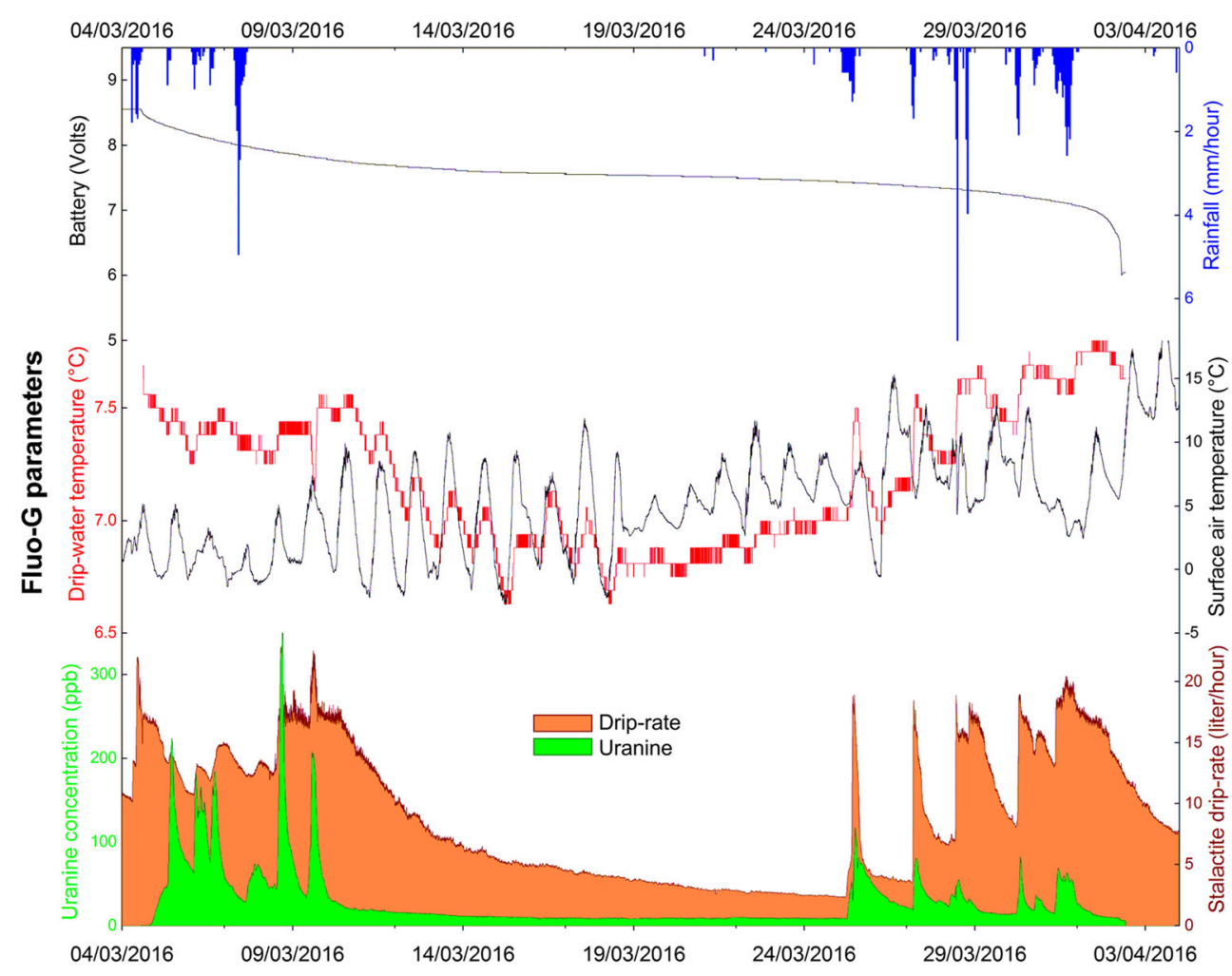

\section{Conclusions}

simplifies the handling on the field as described by Schnegg and Doerfliger (1997) for the GGUN FL-30. For both kinds of devices, the acquisition, calibration and display of data are easy.

As mentioned previously, the Fluo-G has been especially designed regarding the specific objectives and context of karst tracing with geographical/hydrogeological issues. Some advantages arise given its conception. The size and portability make it easy to handle by only one person even in difficult caves. It can be turned-on at the surface and carried in a small bag. The other kinds of devices are often heavy and/or oversized for most of the caves and are better used in karst springs or easily accessible karst systems. The simplified design guarantees a low energy consumption and allows an extended autonomy with small batteries, which can be useful for long-term tracing in remote areas. Finally, the production costs tend to be minimal which should represent a major advantage for potential users.

The Fluo-G is under constant development and improvements are necessary despite the first good results. The capabilities of this version are intentionally limited compared to currently available commercial solutions. It was designed for uranine only since it is the most used dye by speleologists and karst hydrogeologists. It does not have the capabilities to measure simultaneous dyes like the GGUN FL30. Another disadvantage of the Fluo-G is the data collection. Since it is a 2-in-1 system, the device must be out of the water for data reading; however, a simple handling allows a quick reading of the data and the rebooting of the system with minimum data losses. Another possible issue is the sealing of the box in case of extreme flood events.
The Fluo-G field fluorometer is a new kind of compact field fluorometer for hydrogeological use. The intent was to create a simple, compact and easy-to-use device. Standard components were required to build a low-cost and simple product. The fluorometer has been tested in a karst environment but can also be used in other hydrological environments that require dye-tracing methodology.

Karst systems and caves offer great opportunities for scientific research and exploration to understand both the functioning and organization of groundwater. In-cave dye tracing can give valuable additional information about the internal structure and hydraulic functioning of karst aquifers (Lauber et al 2014); however, specific conditions inside caves require particular dispositions, which is especially the case for tracer test techniques.

Besides the classic advantages of automatic field fluorometers compared to charcoal bags and water sampling, this device is small, extra-light and energy efficient. The handling is very simple for calibration, data acquisition and results display. The Fluo-G does not have all the capabilities of similar devices used for fluorescence measurement. The purpose was to design a simple and low-cost product for cavers and karst researchers. Uranine, turbidity and temperature are the three parameters that can be measured.

The fluorometer has been successfully tested in the laboratory and in the field and the results are in good fit with other methods in terms of dye concentration, data resolution, precision and accuracy. While the main goal was to get quality data 
in line with the specific issues in karst research, the next step is to ensure the durability of the device regarding the aggressive karst environment. The Fluo-G has so far been tested in different case studies in Belgium. Applications to a larger number of environments, also with different field settings and specific issues will help to highlight capabilities and limitations of the device and will suggest further improvements.

Acknowledgments The development of the Fluo-Green was made possible through the financial support of the Belgium National Fund for Scientific Research (FRS-FNRS) in the framework of the KARAG Project (www.karag.be). The authors would also like to acknowledge N. Goldscheider and an anonymous reviewer for their valuable comments, which helped to improve this manuscript.

Open Access This article is distributed under the terms of the Creative Commons Attribution 4.0 International License (http:// creativecommons.org/licenses/by/4.0/), which permits unrestricted use, distribution, and reproduction in any medium, provided you give appropriate credit to the original author(s) and the source, provide a link to the Creative Commons license, and indicate if changes were made.

\section{References}

Benischke R, Goldscheider N, Smart C (2007) Tracer techniques. In: Goldscheider N, Drew D (eds) Methods in karst hydrogeology. International Contributions to Hydrogeology. Taylor and Francis, London, pp 147-170

Dewaide L, Bonniver I, Rochez G, Hallet V (2016) Solute transport in heterogeneous karst systems: dimensioning and estimation of the transport parameters via multi-sampling tracer-tests modelling using the OTIS (One-dimensional Transport with Inflow and Storage) program. J Hydrol 534:567-578. doi:10.1016/j.jhydrol.2016.01.049

Goldscheider N, Meiman J, Pronk M, Smart C (2008) Tracer tests in karst hydrogeology and speleology. Int J Speleol 37(1):27-40

Käss W (1998) Tracing technique in geohydrology. Balkema, Rotterdam, The Netherlands, $600 \mathrm{pp}$

Lauber U, Ufrecht W, Goldscheider N (2014) Spatially resolved information on karst conduit flow from in-cave dye tracing. Hydrol Earth Syst Sci 18:435-445

Meiman J, Groves C, Herstein S (2001) In-cave dye tracing and drainage basin divides in the Mammoth Cave Karst aquifer, Kentucky. In: Kuniansky E (ed) U.S. Geological Survey karst interest group proceedings. US Geol Surv Water Resour Invest Rep 01-4011, pp 179-185

Poulain A, Rochez G, Bonniver I, Hallet V (2015) Stalactite drip-water monitoring and tracer tests approach to assess hydrogeologic behavior of karst vadose zone: case study of Han-sur-Lesse (Belgium). Environ Earth Sci 74:7685-7697. doi:10.1007/s12665-015-4696-9

Schnegg PA (2002) An inexpensive field fluorometer for hydrogeological tracer tests with three tracers and turbidity measurement. In: Bocanegra E, Martinez D, Massone H (eds) XXXII IAH and ALHSUD Congress on Groundwater and Human Development. Mar del Plata, Argentina, October 2002

Schnegg PA, Doerfliger N (1997) An inexpensive flow-through field fluorometer. In: Proceedings of the 6th Conference on Limestone Hydrology and Fissured Media. La Chaux-de-Fonds, Switzerland, August 1997

Smart C (2005) Error and technique in fluorescent dye tracing. In: Sinkholes and the engineering and environmental impacts of karst. ASCE, Reston, VA, pp 500-512

Smart C, Zabo L, Calvin Alexander E Jr, Worthington SRH (1998) Some advances in fluorometric techniques for water tracing. Environ Monit Assess 53:305-320 